\title{
Н.Г. Соколова
}

\section{МОДЕЛЬ СОЦИАЛЬНОЙ СТРУКТУРЫ ОБЩЕСТВА В ИССЛЕДОВАНИИ КАЧЕСТВА ЖИЗНИ НАСЕЛЕНИЯ ТЕРРИТОРИИ}

В статье рассматриваются проблема поиска модели соииальной структуры общества, отражающей социальное развитие, эффективность жизнедеятельности человека и общества в иелом, в частности в исследовании качества жизни населения территории. Предлагается метод распределения населения по среднедушевому доходу с использованием системы нормативных потребительских бюджетов, который используется в качестве каркаса модели социальной структуры населения территории. На базе информации территориального маркетингового исследования качества жизни населения г. Ижевска, проведенного в мае 2011 г., рассматривается соииальной структуры общества (на примере населения города Ижевск).

Ключевые слова: модель социальной структуры общества, качество жизни населения территории, среднедушевой доход, маркетинг территории

В общенаучном плане развитие представляет собой качественное изменение. Если в процессе развития в системе возрастает количество элементов и подсистем, увеличивается количество связей и взаимодействий, возрастает набор функций, обеспечивающий большую устойчивость системы, то такое развитие системы представляет собой прогресс. Применительно к обществу этот диалектический критерий направленности развития означает, что прогрессивное развитие представляет собой процесс дифференциации, усложнения социальной структуры общества при одновременном повышении уровня взаимосвязи, взаимозависимости классов, социальных слоев, групп, индивидов друг от друга.

Социальное развитие в социально-экономическом плане представляет собой сложный и многомерный процесс повышения эффективности жизнедеятельности человека и общества в целом, выражаемого в качестве жизни населения, изменении качества жизни социальных групп относительно предыдущего состояния, а также относительно состояния качества жизни других социальных групп. Достойное качество жизни при этом определяется относительно качества жизни окружающих человека людей, а также уровнем развития собственных потребностей и ценностными ориентациями. Выявление социальных структур является предпосылкой, а их преобразование - результатом реализации социально-экономических, политических и духовных программ развития общества и повышения качества жизни.
Необходим поиск модели социальной структуры общества, отражающей социальное развитие, эффективность жизнедеятельности человека и общества в целом. Модель социальной структуры становится неотъемлемым элементом категории качества жизни населения, так как позволяет оценивать и анализировать качество жизни в статике и динамике относительно социальных групп и социальных норм.

Практика 1990-х гг. в России, насаждающая европоцентричную модель мотивации жизнедеятельности человека, в качестве ответной реакции людей проявилась в жесткой зависимости качества жизни от уровня жизни. Массовая бедность и низкая обеспеченность предопределили крайне низкое самочувствие населения, рост смертности, снижение рождаемости и др. Социальная стратификация населения в России идет по материальному признаку, и эта тенденция обостряется качественными изменениями дифференциации. Доля низкообеспеченных слоев населения стала доминирующей, дифференциация населения по уровню жизни достигла четырнадцатикратности [7, с. 162], многие исследователи считают ее чрезмерной. Социальная структура становится следствием дифференциации населения по уровню жизни, т. е., в первую очередь, по уровню среднедушевого дохода. Встает вопрос о поиске, подборе или формировании метода дифференциации населения территории по среднедушевому доходу, необходимой и достаточной для целей отражения и анализа качества жизни населения терри- 


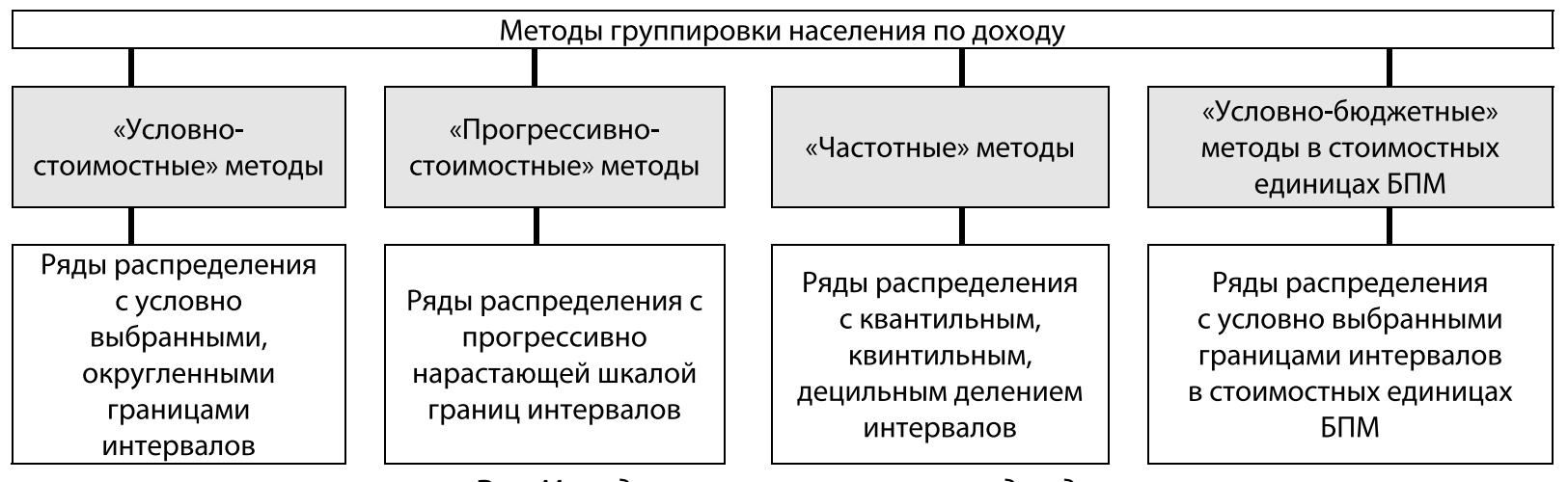

Рис. Методы группировки населения по доходу

тории в статике и динамике относительно социальных групп и социальных норм.

Проанализируем принятые в статистической и исследовательской практике методы группировки или дифференциации населения по доходу. Анализ работ В.Н. Бобкова $[1,7]$, А. Х. Карапетяна [6], И.И. Елисеевой [5], В. Дыбцыной [4], Г. Деева [3] и статистических сборников Госкомстата России [10] позволяет говорить о 4 группах методов дифференциации населения по уровню дохода (рис.).

Первая группа методов формирует ряды распределения с условно выбранными границами интервалов. Они предусматривают деление всего диапазона колебаний дохода на неравные (учитывая неравномерную плотность распределения) интервалы. Ряды с условно выбранными или округленными границами интервалов деления вполне отвечают задаче статистического описания и дифференциации доходов населения, но имеют один крупный недостаток. Выбор точек деления производится по соображениям удобства или округления. Это порождает массу вариантов рядов распределения и препятствует проведению аналитических операций в динамике. Стоимостное измерение границ интервалов не преодолевает инфляционного изменения.

Вторая группа методов формирует ряды распределения, которые используют прогрессивно нарастающую шкалу, и полностью обходит указанный выше недостаток. Вместо «условного» выбора интервалов деления здесь используется система нарастающих по геометрической прогрессии точек деления. Не оспаривая теоретического и практического значения данного ряда распределения, позволяющего описывать вариацию признака со всеми его особенностями, отметим, что для обобщающих представлений и сравнений, особенно в динамике, он также непригоден.
Третья группа методов формирует ряды распределения, использующие квантильные показатели. Если в интервальных рядах задаются границы изменения признака, и соответственно им определяются частоты, то в квантильном, напротив, задаются частоты и определяются границы, в которых они заключены. Наибольшее применение нашли квинтильные и децильные ряды распределения населения по доходам. Их значение велико при сравнении и анализе общей картины распределения населения по доходу, но отсутствие определенной единицы измерения признака приводит к неопределенности образа групп населения и границ интервалов деления населения по доходам.

Четвертая группа методов формирует ряды распределения, использующие уровень прожиточного минимума в качестве единицы измерения границ интервалов деления. В работах В.Н. Бобкова [7], В. Дыбцыной [4, с. 74], Г. Деева [3, с. 11], А.Ю. Чернова [12, с. 11] и в работах прошлых лет автора данного исследования $[8,9$, с. 74$]$ приводится несколько вариантов данных рядов распределения (табл. 1).

Данные ряды хороши для целей обобщающих представлений и сравнений, в описательных и аналитических исследованиях. Они преодолевают инфляционные изменения, но повторяют недостаток рядов распределения с условно выбранными границами интервалов деления. Неизвестно, на каком основании производится тот или иной выбор точек деления интервалов, в чем причина их изменения, каковы границы интервала «на уровне прожиточного минимума». Необходим метод дифференциации, который бы позволил анализировать социальную структуру общества (уровень и динамику качества жизни населения территории) в динамике дохода и времени, т. е. ряд распределения должен содержать образные группы со стоимостными 
Таблица 1

Варианты рядов распределения, использующих уровень бюджета прожиточного минимума (БПМ) как единицу измерения среднедушевого дохода

\begin{tabular}{|c|c|c|c|c|c|c|c|}
\hline $\begin{array}{l}\text { Автор, предложивший } \\
\text { ряд распределения }\end{array}$ & \multicolumn{7}{|c|}{$\begin{array}{c}\text { Варианты рядов распределения и границы интервалов деления населения по среднеду- } \\
\text { шевому доходу }\end{array}$} \\
\hline \multirow{2}{*}{ В. Дыбцина (1995) } & \multirow{2}{*}{$\begin{array}{c}\text { Ниже } \\
\text { БПМ }\end{array}$} & \multirow{2}{*}{$\begin{array}{c}\text { На уровне } \\
\text { БПМ }\end{array}$} & \multicolumn{5}{|c|}{ Выше уровня БПМ } \\
\hline & & & до 1,5 & 1,5 до 2,0 & 2,0 до 3,0 & 3,0 до 5,0 & Свыше 5,0 \\
\hline Г. Деев (1992) & до 0,5 & до 1,0 & \multicolumn{3}{|c|}{$1,0-2,5$} & $2,5-4,0$ & Свыше 4,0 \\
\hline Г. Деев (1994) & до 0,5 & до 1,0 & $1,0-1,5$ & \multicolumn{2}{|c|}{$1,5-2,5$} & $2,5-4,0$ & Свыше 4,0 \\
\hline А. Ю. Чернов (1995) & \multicolumn{2}{|c|}{ до 1,01} & \multicolumn{2}{|c|}{$1,0-1,8$} & $1,8-3,6$ & $3,6-5,4$ & Свыше 5,4 \\
\hline Н. Г. Соколова (2000) & до 0,7 & $0,7-1,0$ & $1,0-1,4$ & $1,4-1,8$ & $1,8-3,6$ & $3,6-5,4$ & Свыше 5,4 \\
\hline В. Н. Бобков (2007-2009) & \multicolumn{2}{|c|}{ до 1,0} & \multicolumn{2}{|c|}{$1,0-2,0$} & \multicolumn{2}{|r|}{$2,0-7,0$} & Свыше 7,0 \\
\hline
\end{tabular}

измерениями границ интервалов, при этом ряд должен преодолевать инфляционные изменения. Вышеуказанные методы группировки в чистом виде или устарели (потеряли актуальность, не отражают действительности), или не формируют ряд распределения, отвечающий вышеизложенным требованиям.

Нами предлагается модель социальной структуры общества на основе метода дифференциации населения по среднедушевому доходу с применением нормативных потребительских бюджетов, порождающих ряд распределения с объективно выбранными границами интервалов. Она основана на следующих положениях:

1) стоимостной единицей измерения границ интервалов является величина прожиточного минимума, или БПМ, уровень которого закреплен законодательно [11], имеет региональную дифференциацию [2], позволяет преодолевать инфляционные изменения;

2) объективность выбора границ интервалов деления базируется на системе нормативных потребительских бюджетов В.Н. Бобкова $[1,7]$, активно используемых во Всероссийском центре уровня жизни:

- бюджет прожиточного минимума как черта абсолютной бедности и восстановительный потребительский бюджет (ВПБ) - бюджеты низкого достатка;

— потребительский бюджет среднего достатка, или средних стандартов жизни (ПБСД);

- потребительский бюджет высокого достатка (ПБВД);

3) данные бюджеты создают систему социальных стандартов качества жизни, минимальных гарантий и ориентиров. С нашей точки зрения, границы данных бюджетов (а не их нормируемое наполнение) могут служить основой для определения социальных норм (стандартов) развития человека, семьи, социальных групп и об- щества в целом, а также нормами (стандартами) уровня ресурсов, необходимых для обеспечения того или иного качества жизни населения. Пропорция, введенная В.Н. Бобковым между БПМ, ВПБ, ПБСД и ПБВД как 1:2:7 (2007 г.) [7, с. 605] или 1:2:6:11 (2009 г.) [1, с. 7] принимается и развивается далее;

4) структуры «законодательного» и предложенного В.Н. Бобковым БПМ неидентичны, его стоимостная оценка отличается периодически на 1,5-2,0\%. В данном исследовании предпочтение отдается уровню (величине) «законодательного» БПМ по причине его открытости и универсальности;

5) во-первых, развивается идея А.Ю. Чернова [12] относительно целесообразности наименования групп населения для их образного представления, во-вторых, оптимизируется для целей анализа ряд распределения путем его большего дробления.

Метод распределения населения по среднедушевому доходу и каркас для создания модели социальной структуры населения для целей отражения и анализа качества жизни населения территории в статике и динамике относительно социальных групп и социальных норм представлен в таблице 2 .

Предложенный ряд распределения создает объективные образы социальных групп с разным уровнем среднедушевого дохода:

1 группа — «бедные / наиболее нуждающиеся» индивиды и семьи, среднедушевой доход которых ниже стоимостной оценки бюджета прожиточного (БПМ).

2 группа - «низкообеспеченные» индивиды и семьи, среднедушевой доход которых находится в интервале между стоимостной оценкой 1БПМ и 2БПМ. Внутри первой и второй социальных групп возможно удовлетворение лишь насущных потребностей, позволяющих 
Таблица 2

Метод распределения населения по среднедушевому доходу и каркас модели социальной структуры населения территории

\begin{tabular}{|c|c|c|c|c|}
\hline $\begin{array}{c}\text { № } \\
\text { группы }\end{array}$ & \multicolumn{2}{|c|}{$\begin{array}{c}\text { Условное наименование социаль- } \\
\text { ной группы }\end{array}$} & $\begin{array}{l}\text { Интервал стоимостных оценок } \\
\text { среднедушевого дохода, БПМ }\end{array}$ & $\begin{array}{c}\text { Интервал стоимостных оценок } \\
\text { среднедушевого дохода, руб. (БПМ } \\
\text { Удмуртской Республики I кв. } 2011 \text { г. } \\
\quad-5600-00)\end{array}$ \\
\hline 1 & \multicolumn{2}{|c|}{ Бедные / Наиболее нуждающиеся } & До 1 БПМ & $0-5600$ \\
\hline \multicolumn{5}{|c|}{ Граница минимальных гарантий } \\
\hline 2 & \multicolumn{2}{|c|}{ Низкообеспеченные } & От 1 БПМ до 2 БПМ & $5601-11200$ \\
\hline \multicolumn{5}{|c|}{ Граница минимально-восстановительных гарантий } \\
\hline 3 & \multirow{2}{*}{ Среднеобеспеченные } & I & От 2 БПМ (ВПБ) до 4 БПМ & $11201-22400$ \\
\hline 4 & & II & От 4 БПМ до 6 БПМ & $22401-33600$ \\
\hline \multicolumn{5}{|c|}{ Граница ориентиров - «средний класс» } \\
\hline 5 & \multicolumn{2}{|c|}{ Обеспеченные } & От 6 БПМ (ПБСД) до 11 БПМ & $33601-61600$ \\
\hline 6 & \multicolumn{2}{|c|}{ Высокообеспеченные } & От 11 БПМ (ПБВД) и выше & 61601 и более \\
\hline
\end{tabular}

компенсировать затраты легкого, простого ненапряженного труда. В группах происходит ограничение социализации индивидов в трудовой сфере, затруднено выполнение социальных ролей родителей.

3 и 4 группы - «среднеобеспеченные» индивиды и семьи, среднедушевой доход которых находится в интервале между стоимостной оценкой 2БПМ - воспроизводительного потребительского бюджета (ВПБ) и 6МПБ. Для более подробного анализа группа «среднеобеспеченные» разделена на две подгруппы по интервалам до 4БПМ и 6БПМ. Внутри данной социальной группы возможно обеспечение социальной интеграции основной массы индивидов в жизнь общества, социализация в трудовой сфере, содержание детей и простое воспроизводство общества;

5 группа - «обеспеченные» индивиды и семьи, среднедушевой доход которых находится в интервале между стоимостной оценкой 6БПМ, или потребительского бюджета среднего достатка (ПБСД), и 11БПМ - средний слой общества, или так называемый «средний класс», обладающий потребительским бюджетом среднего достатка. Жизнь индивидов данной группы основана на сложном, высококвалифицированном труде и предпринимательских способностях, ориентирована на участие взрослых в воспитании своих детей и молодого поколения, общественную деятельность;

6 группа - «высокообеспеченные» индивиды и семьи, среднедушевой доход которых превышает 11БПМ и является бюджетом высокого достатка, обеспечивающего удовлетворение потребностей высокоразвитых личностей и членов их семей, умножение индивидуального и общественного потенциала. В данной социальной группе возможно максимальное удовлетворение потребностей творчества и самореализации, жизнедеятельность индивидов группы направлена на социальную, интеллектуальную и духовную интеграцию общества и его расширенное воспроизводство.

В рамках маркетинговых исследований территории, в частности посвященным анализу качества жизни населения города, данная модель социальной структуры нашла свое применение. Позволила в статике проиллюстрировать качество жизни населения города относительно социальных групп и социальных нормативов. В таблице 3 отражена социальная структура населения г. Ижевска.

Генеральная совокупность территориального маркетингового исследования - это население г. Ижевска. Демографическая статистика показывает, что численность населения г. Ижевска на начало 2011 г. составляет около 624000 человек. Охват генеральной совокупности обеспечивается выборкой по домохозяйствам. Принято: элемент совокупности - домохозяйство; единица совокупности - члены домохозяйства, достигшие 18 лет. Расчетный размер выборочной совокупности по домохозяйствам определен 400 единицами (при условии, что коэффициент доверия равен 2, выборочная дисперсия - 0,5, предельная ошибка выборки 5\%). Размер проектной выборки в процессе формирования структуры выборки увеличивается и ограничивается 489 единицами. Для обеспечения репрезентативности и случайности попадания респондентов в выборку применяется страти- 
Социальная структура общества (населения г. Ижевска, май-июнь 2011 г.)

\begin{tabular}{|c|l|c|c|c|}
\hline $\begin{array}{c}\text { № } \\
\text { группы }\end{array}$ & $\begin{array}{c}\text { Условное наименование соци- } \\
\text { альной группы }\end{array}$ & $\begin{array}{c}\text { Интервал стоимостных оценок } \\
\text { среднедушевого дохода, руб. }\end{array}$ & Доля, \% & $\begin{array}{c}\text { Численность население } \\
\text { г. Ижевска по группам, чел. }\end{array}$ \\
\hline 1 & Бедные / наиболее нуждающиеся & $0-5600$ & 3,8 & 23712 \\
\hline 2 & Низкообеспеченные & $5601-11200$ & 23,9 & 149136 \\
\hline 3 & Среднеобеспеченные I & $11201-22400$ & 43,2 & 269568 \\
\hline 4 & Среднеобеспеченные II & $22401-33600$ & 18,8 & 117312 \\
\hline 5 & Обеспеченные & $33601-61600$ & 8,2 & 51168 \\
\hline 6 & Высокообеспеченные & 61601 и более & 2,1 & 13104 \\
\hline Итого & - & - & $\mathbf{1 0 0 , 0}$ & $\mathbf{6 2 4 0 0 0}$ \\
\hline
\end{tabular}

фикация потребителей по пяти районам города и четырнадцати типам домов. Структура генеральной совокупности по районам и типам домов переносится на структуру выборочной совокупности. Выбранный механизм попадания в выборку — «правило улитки». Рекомендуемый промежуток времени для проведения опроса время между 16 и 20 часами. Опрос проведен в мае-июне 2011 г., фактическая численность обследованных домохозяйств после ремонта выборки - 400 единиц, число респондентов, охваченных обследованием - 1042 чел.

Полученной в результате массового потребительского опроса информации достаточно для отражения социальной структуры и дальнейшего анализа качества жизни населения города. Следует отметить, что оценка качества жизни исследуемой территории на базе полученной репрезентативно информации является достоверной, так как фактическая ошибка выборки 4,0\% соответствует норме. Предложенный метод распределения позволяет создать модель социальной структуры населения территории на основе анализа среднедушевых доходов и их соответствия системе потребительских бюджетов разного уровня достатка, минимальным гарантиям и ориентирам.

\section{Список источников}

1. Бобков В. Н. Вопросы теории, методологии изучения и оценки качества и уровня жизни населения // Уровень жизни населения регионов России. - 2009. - №6. - С. 3-15.

2. Величина прожиточного минимума за I квартал 2011 года // Федеральная служба государственной статистики. [Электронный ресурc]. URL: http://www.gks.ru/gis/tables/UROV-6.htm (дата обращения 04.05.2011).

3. Деев Г. Модель распределения населения по доходам // Вопросы статистики. - 1995. - №5. - С. 3-15.

4. Дыбцина В., Шашнов С. О социально-экономической дифференциации населения и уровне бедности в Российской Федерации и ее отдельных регионах // Вопросы статистики. 1995. №2. с. 73-76.

5. Елисеева И. И., Юзбашев М. М. Общая теория статистики : учеб. пособие / Под ред. И. И. Елисеевой. - М. : Финансы и статистика, 1996. - $368 \mathrm{c}$.

6. Карапетян А. Х. Доходы и потребление населения СССР / Под ред. Н. М. Римашевской. - М. : Статистика, 1980. $-272 \mathrm{c}$

7. Качество и уровень жизни населения в новой России. 1991-2005 гг. / Бобков В. Н., Горлов И. С., Гулюгина А. А. и др. - М. : ВЦУЖ, 2007. - 719 с.

8. Соколова Н. Г. Совершенствование управления в социальной сфере на основе системы дополнения информации о личном потреблении населения: дис. ... канд. экон. наук. - Ижевск : ИжГТУ, 2000. - 195 с.

9. Соколова Н. Г. Формирование системы дополнения информации о личном потреблении населения в муниципальном управлении. - Екатеринбург; Ижевск : Ин-т экономики УрО РАН, 2008. - 189 с.

10. Социально-экономическое положение и уровень жизни населения России в 2008 г. : стат. сб-к. - М. : Росстат, $2008,-502$ c.

11. Федеральный закон от 24 октября 1997 г. №134-Ф3 «О прожиточном минимуме в Российской Федерации» [С изменениями от 27 мая 2000 г., 22 августа 2004 г., 24 июля 2009 г.]. [Электронный ресурс]. Доступ из справ.-правовой системы «КонсультантПлюс».

12. Чернов А. Ю. Личные финансы. Доходы и расходы семейного бюджета. - М. : Перспектива, 1995. - 176 с.

\section{Информация об авторе}

Соколова Надежда Геннадьевна (Ижевск) - кандидат экономических наук, доцент кафедры экономики, технологии и управления коммерческой деятельностью ГОУ ВПО «Ижевский государственный технический университет» (426069, Удмуртская Республика, г. Ижевск, ул. Студенческая, 7, e-mail: sokol4@udm.net). 
N. G. Sokolova

Ph. D. in Economics, associate professor Izhevsk State Technical University

\section{Model of social structure in the study of life's quality of the territory's population}

This article discusses the problem of finding a model of social structures reflecting social development, the effectiveness of human life and society in general particularly in the study of life's quality of the territory. The method of distribution of population by average per capita income using a system of normative consumer budgets which is used as a frame model of the social structure of the territory. On the basis of information of the territorial marketing research quality of life in Izhevsk conducted in May 2011 is considered the model of social structure (population of Izhevsk).

Keywords: model of social structure of the society, the quality of population's life of the territory, average per capita income, marketing of the territory

\section{References}

1. Bobkov V. N. (2009). Voprosy teorii, metodologii izucheniya i otsenki kachestva i urovnya zhizni naseleniya [Questions of theory, methodology for studying and evaluating the quality and standard of living]. Living standards in Russia's regions, 6, 3-15.

2. Federal'naya sluzhba gosudarstvennoy statistiki (2011). Velichina prozhitochnogo minimuma za I kvartal 2011 goda [Federal State Statistics Service. Living wage for the I quarter of 2011]. Retrieved from http://www.gks.ru/gis/tables/UROV-6.htm

3. Deev G. (1995). Model' raspredeleniya naseleniya po dokhodam [Model of the population distribution depending on the income]. Questions of statictics, 5, 3-15.

4. Dybtsina V., Shashnov S. (1995). O sotsial'no-ekonomicheskoy differentsiatsii naseleniya i urovne bednosti v Rossiyskoy Federatsii i ee otdel'nykh regionakh [On the socio-economic stratification of the population and poverty in the Russian Federation and its regions]. Questions of statistics, 2, 73-76.

5. Eliseeva I. I., Yuzbashev M. M., Eliseeva I. I. (Ed.) (1996). Obshchaya teoriya statistiki: ucheb. posobie [The general theory of statistics: a tutorial]. Moscow: Finances and Statistics.

6. Karapetyan A. Kh., Rimashevskaya N. M. (Ed.) (1980). Dokhody i potreblenie naseleniya SSSR [Population of the USSR: income and consumption]. Moscow: Statistics.

7. Bobkov V. N., Gorlov I. S., Gulyugina A. A. et. al. (2007). Kachestvo i uroven’ zhizni naseleniya v novoy Rossii. 1991-2005 [The quality and standards of living in the new Russia. 1991-2005]. Moscow: VCUG.

8. Sokolova N. G. (2000). Sovershenstvovanie upravleniya v sotsial'noy sfere na osnove sistemy dopolneniya informatsii o lichnom potreblenii naseleniya [Improving governance in the social sector on the basis of the system to supplement the information on personal consumption. Ph. D. thesis]. Izhevsk: Izhevsk State Technical University.

9. Sokolova N. G. (2008). Formirovanie sistemy dopolneniya informatsii o lichnom potreblenii naseleniya v munitsipal'nom upravlenii [Formation of the system to supplement the information on personal consumption in municipal management]. Ekaterinburg, Izhevsk: Institute of Economics, UB RAS.

10. Rosstat (2008). Sotsial'no-ekonomicheskoe polozhenie i uroven' zhizni naseleniya Rossii v 2008 [Socio-economic status and living standards in Russia in 2008]. Moscow: Rosstat.

11. Federal'nyy zakon ot 24 oktyabrya 1997 g. №134-FZ «O prozhitochnom minimume v Rossiyskoy Federatsii» (Sizmeneniyami ot 27 maya 2000 g., 22 avgusta 2004 g., 24 iyulya 2009 g.) [Federal Law of October 24, 1997 № 134-FZ “On Subsistence Minimum in Russian Federation" [As amended May 27, 2000, August 22, 2004, July 24, 2009]. Retrieved from legal reference system «Consultant Plus».

12. Chernov A. Yu. (1995). Lichnye finansy. Dokhody i raskhody semeynogo byudzheta [Personal finances. Income and expenses of the family budget]. Moscow: Perspective.

\section{Information about the author}

Sokolova Nadezhda Gennad'evna (Izhevsk) - Ph. D. in Economics, associate professor at the Chair for economics, technology and commercial activity management, Izhevsk State Technical University (426069, the Republic of Udmurtia, Izhevsk, Studencheskaya St. 7, e-mail: sokol4@udm.net). 